\title{
Using community-mediated learning tools for informal learning online
}

\author{
Jenny Eppard \\ University of Virginia, \\ Curry School of Education, \\ 205 F Street Shenandoah, \\ Virginia 22849, USA \\ Email: jrk3r@virginia.edu
}

\begin{abstract}
Individuals are using the internet in increasing numbers to engage in informal learning either alone or in a group. This study aims to determine which types of learning tools participants used in a specific online community to negotiate possible learning. The scope of this study was not to determine if learning occurred but to provide insight into the tools used in an online community that encompassed characteristics of learning. The methodology was a qualitative case study including detached observations, participant observations, interviews and document analysis. The study found that there were two types of learning tools used on the blog cognitive (discourse, action, reflection and checking for accuracy) and physical (text, videos, images and links).
\end{abstract}

Keywords: activity theory; artefacts; informal learning; learning tool; social media.

Reference to this paper should be made as follows: Eppard, J. (2017) 'Using community-mediated learning tools for informal learning online', Int. J. Social Media and Interactive Learning Environments, Vol. 5, No. 1, pp.32-47.

Biographical note: Dr. Jenny Eppard has recently earned a $\mathrm{PhD}$ in Instructional Technology from the University of Virginia. She is interested in various aspects of instructional technology and works on numerous projects related to the field such as flipped learning, learning through social media and mobile learning applications. She currently holds the title of Assistant Professor at a university in the Middle East.

\section{Introduction and background information}

Informal learning has been defined "as learning that lacks systematic support explicitly organized to foster learning" (Marsick, 2009). Jokisalo and Riu (2009) claimed that formal learning includes goals and the process of learning emerge through the experience rather than planned in advance. Informal learning as explained by Livingstone (2001, p.4) is: ".... any activity involving the pursuit of understanding, knowledge or skill which occurs without the presence of externally imposed curricular criteria". These definitions are fairly broad and lack any real theoretical or practical specificity.

In an attempt to create a narrower definition of informal learning, Schugurensky (2006) argued that informal learning is:

Copyright (C) 2017 Inderscience Enterprises Ltd. 
1 self-directed (self-direction informal learning can include a resource person who may not be an educator)

2 incidental, which means it occurs without the express purpose of learning but it is conscious

3 social (internalisation) and unconscious.

Research on informal learning includes a meta-analysis conducted at Leeds University. According to the authors, Colley, Hodkinson and Malcom (2002, p.16), informal learning involves the characteristics shown in Figure 1.

Figure 1 Characteristics of informal learning (see online version for colours)

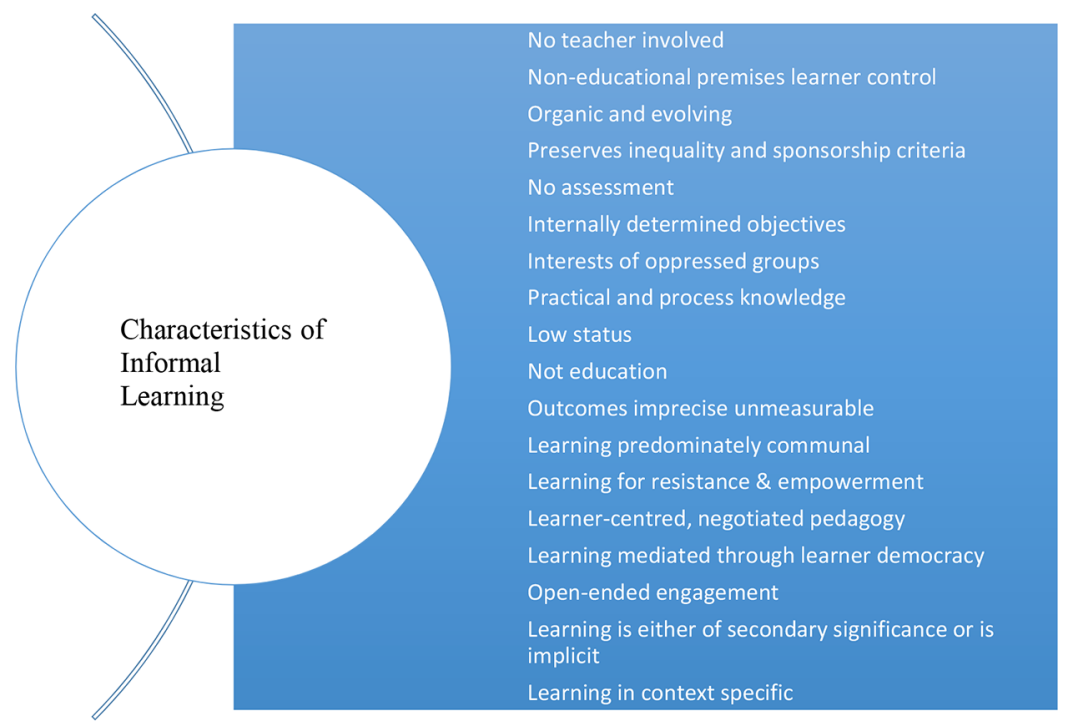

Several of these characteristics are substantiated by or added to by other scholars as well. Laurillard (2007) argued that informal learning lacks structure or a formal teacher-student relationship. He also maintained that informal learning could occur at any time and at any place either individually or in conjunction with other participants. Other researchers emphasise the contextualisation of informal learning strategies and approaches. Marsick (2009, p.273) stated that informal learning is "affected by beliefs, values, histories and prior socialization". Other factors that mediate informal learning are context, relationships and hierarchical structures (Marsick, 2009). Siemens (2004) claims that future learning will include more informal learning than formal learning.

As information provided on the internet is possibly on the rise due to a surge in the number of websites (Internet Live Stats, n.d.) many people are now using the internet as a medium for informal learning (Selwyn, 2008). Research shows that learning through social media sites is self-regulated (McLoughlin and Lee, 2010). There are several advantages to learning informally through the internet. For example, the internet is flexible and quick. Individuals can often exchange information instantly from any venue home, work, the mall. All that is needed is access to an internet connection.

This learning can take place by participating in online communities. Ziegler, Paulus and Woodside (2014, p.74) found that participants in an informal online community 
developed meaning together as they "noted their experiences, reinterpreted these experiences together, theorized by creating abstractions and explanations and questioned the assumptions of others", found that informal learning in online communities takes place when it was learner driven and motivated by finding a solution(s) to a problem. Also, the learning was prompted by interest in a topic, which was researched through a search engine. In Attwell's study, those who participated in online communities or through other means of seeking solutions to a problem were interested in social media sites that provide expertise that is not too easy to understand or redundant, but that is not too difficult to understand either. The information of the site needs to connect to and add upon some prior knowledge. Vygotsky's Zone of Proximal Development supports this type of learning. Vygotsky (1978, p.86) defines the zone of proximal development as "the distance between the actual developmental level as determined by independent problem solving and the level of potential development as determined through problem solving under adult guidance, or in collaboration with more capable peers".

There are numerous definitions of virtual communities (I use the terms online community and virtual community interchangeably). Probably the most noted definition is the one provided by Rheingold (1994):

\begin{abstract}
virtual communities are cultural aggregations that emerge when enough people bump into each other often enough in cyberspace. A virtual community is a group of people who may or may not meet one another face-to-face, and who exchange words and ideas through the mediation of computer bulletin boards and networks (pp.57-58)
\end{abstract}

Preece (2001, p.3) defined online communities as "any virtual social space where people come together to get and give information or support, to learn, or to find company. The community can be local, national, international, small or large". Stone claimed that virtual communities are "a passage point for collections of common beliefs and practices that united people who were physically separated" (Stone, 1991, p.85). According to Blanchard (2008, p.1), virtual communities are defined as "groups of people who interact primarily through e-collaboration technologies and who have developed feelings of belonging, identity, attachment and influence with each other". Put otherwise, virtual communities are generally defined as virtual spaces where individuals with a common interest meet using the internet as a medium instead of gathering in person and where there is some degree of familiarity. Participants in these groups may be from different backgrounds, cultures, genders and ages. Virtual communities are often dynamic, physically borderless and can evolve instantly.

The origins of a virtual community can be traced back to as early as 1968 (Tsekeris and Koskinas, 2011, p.41). However, virtual communities as a platform for public expression did not receive much attention until 1993 when Rheingold said "the vision of a citizen designed, citizen-controlled, worldwide communications network is a version of technological utopianism that could be called the vision of the "electronic agora" (Rheingold, 1993, Introduction). Sicilia and Palazón (2008, p.258) emphasised the farreaching effects of online communities when they said: "communities are no longer restricted to geographical limitations...". Their reach is potentially infinite.

One of the drawbacks to use the internet as a vehicle for informal learning is that people can often learn wrong information (e.g., individuals who try to self-medicate without the consent or knowledge of a trained physician). The main problem that occurs when researching informal learning in general is that it is difficult to establish a 
framework for informal learning because it is "hard to standardize, systemize or assess" (Marsick, 2009, p.265). In addition, informal learning is difficult to link to outcomes.

\subsection{Framework: activity theory}

Activity theory has experienced several generations of changes since its inception. The first generation included three variables: subject, artefact and object, and the relationship between the three. Subject being the learner, artefact the tool used as a mechanism for learning, and the object being the learner's goal. Each subsequent generation added to this basic association.

For the purposes of this study, I focused on the second generation of AT since I was studying one activity system but I wanted to understand the process within a greater context than that provided when using the first generation. The second generation of AT was based on the work of Vygotsky's student, Alexei Leontiev. Some of Vygotsky's other students, such as Luria, Galperin, Zaporzets, El-Khonin, also contributed to this version of AT (Bedny, Seglin and Meister, 2000, p.170). According to Lecusay, Rossen and Cole (2008), the second generation of AT materialised because Leont'ev believed that the initial framework as proposed by Vygotsky was too narrow and focused entirely on the individual. Leont'ev believed that learning took place within a context and a community that was much larger than the individual (Lecusay, Rossen and Cole, 2008, p.94).

In addition to tools, subject and object, the second generation included community, rules and division of labour and outcomes. In order to understand the basic structure of the second generation of AT, Engostrom provided the example illustrated in Figure 2.

Figure 2 Second generation of Activity Theory (Engestrom, 2001, p.135)

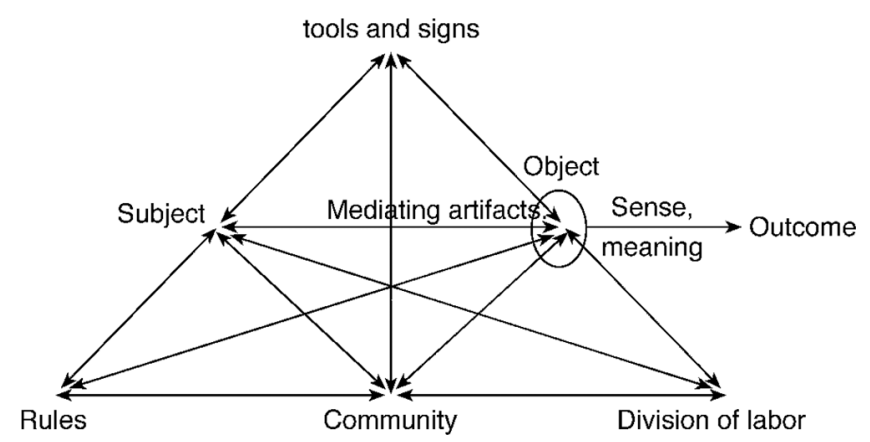

For the purpose of this study, I concentrated on the type of artefacts (tools and signs) used in an online community. To some extent, I evaluated the connection between subject and artefact in an online informal community, but I mostly concentrate on the types of artefacts used in this particular context.

According to AT, tools have a mediating role in the learning process and are a central component of any activity (Kuutti, 1996; Jonassen and Rohrer-Murphy, 1999). Tools, or artefacts, can be defined as any instrument used to facilitate learning. Nardi (1996, p.66) noted "activity cannot be understood without understanding the role of artifacts in everyday existence, especially the way that artifacts are integrated into social practice". Lecusay, Rossen and Cole (2008, p.93) specifically highlighted the historical role of 
artefacts in activities: "It is a medium in which human beings live - an environment composed of and transformed by the artifacts of prior generations extending back to the beginning of the species...The basic function of these artifacts is to coordinate human beings with the physical world and each other". Engestrom supported the importance of artefacts in activities when he stated that activity is primarily a "collective, systematic formation that has a complex meditational structure" (as sited in Daniels, 2001, p.86). It is important to note, however, that artefacts do not replace mental processes but are essential in "shaping and transforming them" (Lecusay, Rossen and Cole, 2008, p.95).

The definition of a tool can be vague. Jonassen and Rohrer-Murphy (1999, p.63) stated that "tools can be anything used in the transformation process". Transformation here means the catalyst for learning. They can include "instruments, signs, procedures, machines, methods, laws, forms of work organization" (Nardi, 1996, p.26). They can also consist of intangible items as well, such as the spoken word and psychological tools (Daniels, 2001). Central to my study is the exploration of the tools used in an online community as an integral part of the informal learning process that is occurring. While there is much research provided into the characteristics of informal learning and research into the notion of learning in online communities, there have not been studies into the artefacts used for possible learning in informal learning communities.

Marsick (2009) hypothesised that the chaos of informal learning could be systematically broken down and organised using a theory akin to Activity Theory as a unit of analysis:

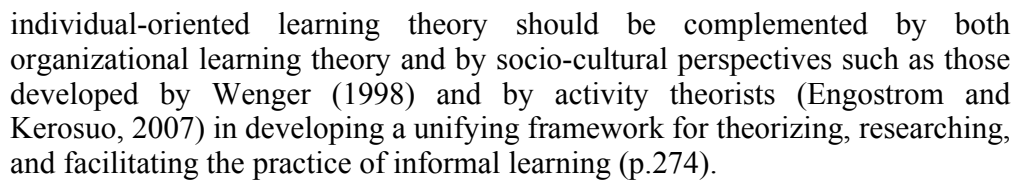

Activity Theory has much to contribute to the study of informal learning. For example, the structure of Activity Theory is flexible. AT provides a general overarching explanation of the data without stringently marrying the results to any one category. Therefore, using AT as a unit of analysis when researching informal learning, which is often dynamic, is beneficial due to its ability to transform and adapt based on the context.

\subsection{Research questions}

RQ1: What evidence shows that informal learning occurs?

RQ2: Which types of learning tools, within the context of AT, are used?

The purpose of this study was not to analyse the data from a political perspective but to better understand the mechanisms of learning through artefacts in on online community that focuses on a current event.

\section{Research methods and data collection}

I used qualitative research techniques as a guide for my research design and implementation. In accordance with this paradigm, I used document analysis (web page analysis), detached observations, participant observations and interviews as a part of the 
data collection and triangulation process after which I used categories and codes to explain the findings. These were used as a means to understand an experience contextually and not in complete isolation. I propose that qualitative research is preferable to quantitative research in this study in that qualitative research lends itself to exploratory research that is descriptive and context rich. This is particularly beneficial since the scope of my research is new to this particular site. A subsection of qualitative research and constructivism is a case study, which was used during this research, especially for data collection.

I applied homogeneous sampling techniques when selecting subjects for the observations. The population under consideration contained bloggers who partook in a particular news blog during the times that I engaged in observations and took field notes. They participated by commenting on the blog or by responding to the comments made by other members. Bloggers who did not make comments were not included since logistically it was difficult to make contact with these members. I took field notes on their comments during the detached and participant observations. The only criterion that I used during the observations was that the subjects must have posted on the blog during the time that I was observing them. If I were to have narrowed the criteria for subject selection further during the observations, I would have forgone crucial content, context and exchanges.

As for the interviews, I first sent out a blog post asking for volunteers. In the end, I interviewed everyone who agreed to be interviewed which was 10 bloggers. Fortunately, the interviewees represented various members of the blog each with their own individual role. I interviewed two passive participants but was unable to interview pro-Assad bloggers because they did not answer my call for participation.

The interviews took place at the end of the data collection period and concurrent with it. Interviews conducted during the data collection stage of this research took place privately. There were a set of previously written questions to be used as a basis for the interview but less formal and less structured questions emerged during the interview when explanation and elaboration were needed.

\subsection{Setting}

The initial setting was a mainstream news blog but later, after the original blog closed down, I moved to an independent blog, about the same topic, developed by disgruntled members of the news blog. Therefore, the continuation of the members from one blog to another on the same topic constitutes a community. I monitored and participated in this community from June 2011 until January 2013. I chose this blog because of its high traffic level and its long-term existence. There were two other blogs that the news site hosted for an extended period of time, but both blogs were problematic for conducting research. The comments made on one of the blogs daily were sometimes in the thousands while the comments made on the other blogs were often less than 50 . The numbers on the blog I chose were more manageable than either of the other blogs. I believed that this particular blog was useful in creating a storyline and in understanding the context indepth. I later moved to an independent blog since the original blog closed down and the community migrated to the new blog.

My goal for subject selection was to focus on individuals that best provided the data needed to determine if informal learning was taking place and to have a deeper 
understanding about how learning occurs in an online community. Much of this data were derived from subject-to-subject interaction and through researcher-to-informant dialogue.

I applied homogeneous sampling techniques when selecting subjects for the observations. The population under consideration contained bloggers who partook in the blogging community during the times that I engaged in observations and took field notes. They participated by commenting on the blog or by responding to the comments made by other members. Bloggers who did not make comments were not included since logistically it was difficult to make contact with these members. I took field notes on their comments during the detached and participant observations.

The only criterion that I used during the observations was that the subjects must have posted on the blog during the time that I was observing them. If I were to have narrowed the criteria for subject selection further during the observations, I would have forgone crucial content, context and exchanges. In order to delve deeper into what was being learned and how it was being learned, however, I needed to select particular individuals to interview.

For the interviews, I narrowed my scope and chose specific informants that provided an in-depth understanding of the phenomenon of informal learning in an online community and provided supporting information for the research questions. Informants for interviewing were chosen using intensity sampling (Ritchie and Lewis, 2003, p.79). They were selected based on quantity of comments and/or intensity of comments. Critical case sampling was used as well during the interview phase (Ritchie and Lewis, 2003, p.80). These subjects were chosen because their participation in the AJE's Syria blog suggested that they were good subjects to study in more depth as examples of how learning occurs. Based on the pilot study, I estimated that about 30 subjects would be studied during the participant and detached observations. During interviews, however, the sample size included a minimum of ten informants. Informants were contacted through their external accounts directly or through the secondary blog.

\subsection{Procedure}

\subsubsection{Detached observations}

In the beginning, I collected data for $1-2 \mathrm{~h}$ every other day. Half of my time was spent taking field notes of the public comments and the other half was spent taking field notes of the posts made by the site's staff. Comments were viewed both retroactively and in real time. I decided to randomise the data collected based on timings for the posts made by the blog administrators and location of the posts - from oldest to newest - made on the public commenting portion of the page.

\subsubsection{Participant observation}

In January 2012, I introduced myself to the participants and began participating on the website in order to investigate the data and themes that I collected during the detached observation phase. Initially, I introduced myself and asked basic questions. Later, during the interviews, I asked more in-depth questions. I also limited my question topics to within the goals of this project. I asked participants for individual interviews after I had become a full participant in the community. 


\subsubsection{Interviews}

One function of the interviews was to focus on filling in the information gaps that emerged from the data collected during the observations. The interviews, however, primarily focused on motives for joining the blog and what specifically was learned during participation. The questions also provided insight into the informants' perception of their own learning and their insights into how they were learning. These questions were derived from the literature review, which showed that learning usually takes place within a framework as outlined in Activity Theory. An initial interview was conducted, but follow-up interviews were necessary at least for some of the participants. The venue for interviewees was a social media site or chat room of the informant's choice. The interviews took place at the end of the data collection period and concurrent with it. Interviews conducted during the data collection stage of this research took place privately.

There were a set of previously written questions to be used as a basis for the interview but less formal and less structured questions emerged during the interview when explanation and elaboration were needed. Rubin and Rubin (2005) developed a flexible structure for interview questions procedure that I will utilise as well. According to their structure, questions went from main questions to follow-up questions (more specific) to probes (most specific). From these questions, more specific questions were addressed (mini-tour questions). The primary purpose for the interviews was to delve deeper into the phenomenon. The questions were based on experiences and/or they were hypothetical.

A message was sent out to selected informants with the following information based on Crang and Cook's (2007) outline:

1 Details about yourself, your institutional affiliation and what your research is about.

2 Who and/or what suggested that she/he be contacted as someone who has important knowledge about this subject.

3 The fact that you would therefore like to talk with her/him at a mutually convenient time and place.

4 That you would like to record the conversation.

5 That everything said would be treated, if necessary, in the strictest confidence.

6 That all efforts would be made in the final text to mask her/his identity... (p.62).

Topics for the questions were derived from the literature and from the pilot study. Other questions developed after data collection and during the interview. The questions were considered as a guide and the questions used in the study, therefore, were semi-structured.

\subsubsection{Research diary}

Spradley (1980, p.71) in Participant Observation claimed that a research journal is "a record of experiences, ideas, fears, mistakes, confusions, breakthroughs and problems that arise during fieldwork". A research diary was kept throughout the study documenting all of these occurrences. It was used more during data collection and analysis than during the literature review. Diary entries were made during the literature review occasionally to 
highlight certain thoughts, but it was not an everyday occurrence like during the data collection/analysis stage. It was included as a part of the data and was included in the analysis as the diary is an integral part of qualitative research since the researcher, like a quantitative test or survey, is considered an instrument (Spradley, 1980, p.72).

\subsection{Analysis}

\subsubsection{Coding}

According to Ritchie and Lewis (2003, p.221), the first step involved in coding is to familiarise yourself with the data set. In this study, a sample of the data from both detached and participation observations and from the interviews was reread in order to identify any gaps, patterns or flaws. This step is crucial in that it emphasises common themes and repetitive ideas (Emerson, Fretz and Shaw, 2005). During this step, thematic patterns and repetitive ideas start to emerge (Emerson, Fretz and Shaw, 2005). Following this initial review, the data that emerged from this study were organised based on categories. Thereafter, the categories were then clustered into classes, referred to as focused coding by Emerson, Fretz and Shaw (2005). This was done using Weft QDA, which is computer software that organises qualitative data.

The categories were organised using taxonomic analysis (Spradley, 1979, p.142) developed using computer software and loosely based on Spradley's model of coding. Data were presented thematically based on the research questions. Snapshots, or vignettes, of common themes were provided and supported with relevant examples. Some of the topics included the division of labour, the rules, the object (or motivation behind participating in the blog) and indicators of informal learning such as responses. Also, I learned about the content and learning tools used on the blog; these were addressed and elaborated on in the write-up.

\section{Findings and discussion}

\subsection{RQ1: what evidence shows that informal learning occurs?}

Driscoll (2000, p.11) defines learning as "a persisting change in human performance or performance potential...[which] must come about as a result of the learner's experience and interaction with the world". However, possible learning on this blog was informal and therefore, behavioural changes were not always apparent. This is true of informal learning in general as Marsick (2009) claimed. Throughout this section, I refer to currently held trends in informal learning in which to position my findings. However, one of the issues with the current research on informal learning is that it is limited to the context or the characteristics of an informal learning environment. There has not been sound research which describes assessing learning in an informal environment at least to my knowledge.

While indications of behavioural changes were not clear, the blog contained much information, which indicated the potential for a learning environment, including cognitive and physical artefacts. The characteristics were present but I did not always have access or the tools needed to genuinely assess learning as indicated through behavioural 
changes. Moreover, evaluating behavioural changes was not the charge of this study nor was it broadly within the scope of this study. Changes in behaviour based on learning needs a formal, separate study to adequately observe changes. This study was an initial overview of possible indications of learning within a specific site.

Possible learning on the blog often came in the forms of constructivist learning, situated learning-legitimate peripheral participation - legitimate peripheral participation and reflection and the tools used reflected these learning styles. Constructivist learning in this context fulfils the following characteristics: "a place where learners may work together and support each other... (the population uses) a variety of tools and information resources, ...pursuit of learning goals and problem-solving activities" (Wilson, 1995, p.25). Therefore, the bloggers collaborated and negotiated the content and context on the blog. As a part of this community, situated learning-legitimate peripheral participation as described by Lave and Wegner (1991) was indicated, although limited and not always obvious. Within this paradigm, novices learn from old-timers who are experts due to their external background or by moving up the system from within the community. This was true on the blog to some extent, depending on an individual's skill. Finally, learning occurred through reflection, in which the subjects became aware of the information or problem and analysed it. Learning was evident through posts that showed question and answers either directly or through problem-solving negotiations, checking the validity of the comments and reflecting on the information, problems or context. This is consistent with finding of Ziegler, Paulus and Woodside (2014) that meaning is developed in informal online communities by questioning the assumptions of each other. The idea of these blogs as a space for learning was evident early on. The blog space provided an area for anyone who wanted to find out information from both mainstream and citizen journalists.

\subsection{RQ2: which types of learning tools, within the context of AT, are used?}

\subsubsection{Learning by doing}

Based on the information collected from the informants, different bloggers who contributed different materials. Some prepared maps while others updated information. Claire was responsible for making and disseminating maps. She claimed that the mapmaking helped her realise that the reports on the blog were usually accurate. Simultaneously, this mapmaking informant served as a fact checker and quality control for a citizen journalist providing reports. The potential for learning was obvious in other areas as well. For example, there were numerous facts that could be learned on the blog. Sandra shared how she learned specific information "...Definitely - the blog added to every - one's knowledge base" [sic] - (interview, June 9, 2012).

Some of the informants described how they learned the importance of, and how to use, social media to collect information and to enact collective change. Cal learned how to use the technology needed to fully participate in a plethora of social media sites.

Before .... I never used twitter or bambuzle or Skype or had any knowledge of disquss software or Vitual proxy Networks or TOR-I learnt as I went along and so did many others to the point where we have set up a blog, published a book (using an internet publishing house) and some are in contact with journalists. A whole group of us had to learn these skills [sic] (interview, June 10, 2012). 
Cal also explained how before he did not know how to use social media and had never used some of the Web 2.0 applications. Angela learned about the power of social media as a catalyst for social transformation. "I learned that social medias can play a great role in spreading the news. ... blog was one of those social media due to its large coverage".

The blog was a virtual centre for learning used to provide detailed information about a specific news story. It also operated as a location to discuss the crises and receive updates from first-hand accounts. Just as importantly, their experience on the blog taught the bloggers about the potential power of virtual communication, and that when used as a learning tool, it has the potential to transform governments and society.

\subsubsection{Checking for accuracy}

Another indication of learning appeared when subjects reported that they were checking for accuracy. Making sure that the information was as correct as possible was one of the collective rules that the group established. There was always someone around to validate the information and if the posts seemed bogus, a trusted blogger could refute the post referring usually to mainstream news organisations, government reports or other trusted sources. Sometimes this could be problematic because scepticism was rife on the blog and many organisations were not trusted. However, by checking the information, the subjects reviewed the information and through a constructivist type of learning, tried to obtain the correct information. Using this paradigm, the learners on the blog collaborated on finding the correct information through a process of self-discovery and a reference to background knowledge.

Through these problem-solving tasks, the bloggers worked collectively to find solutions to quality control issues. Their learning was social, authentic and collaborative (Hung, 2002). If the bloggers did not know the information themselves, they sought the knowledge of an expert who did know the information or could point them in the correct direction. These experts could be on the blog or could be from an external site. Often the expert took the form of someone on the ground or the form of someone who had extensive connections without outside resources, thus forming a web of connections. The importance of fact checking was highlighted in the following comment made by Adam: "Read with a grain of salt until someone else on this site ways the sources are reliable" (January 7, 2012). Theoretically, this type of learning lends itself to situated learninglegitimate peripheral participation where meaning is negotiated and there is a network of experts for different tasks.

\subsubsection{Learning through reflection}

Many of the bloggers showed a certain amount of reflection in their responses to posts that were either questionable or informative. According to Mezirow (1991), reflection occurs on three different levels. The first level involves awareness of a situation. The second level includes an analysis of the situation and the third and final level results in a change in perspective or understanding of the situation. It is uncertain if the bloggers reached the third level very often. The informants claimed that they did not reach this level. However, indications of the first two levels were evident on the blogs. Sometimes, bloggers would read a post and reply immediately, but other times they would reply after they had taken time to research the subject. These reflections could include original posts on the site, videos, images and information cited from external sources. 


\subsubsection{Learning through discourse}

There are several examples of blogging, which demonstrate learning in the community some of which indicate a possible behavioural change. Learning was evident when Andrew posted, one of the blog leaders and perhaps the only consistent member who was reporting from the ground. He did not post often but when he posted the community was very interested in learning from his experiences. To my knowledge, he was never referred to as a troll or spoken to harshly. Andrew continuously provided updates.

In this example, nurse member is searching for information to make sure that her understanding was correct. From this exchange, she received clarification and answers to her questions.

\subsubsection{Physical artefacts}

Artefacts were central to the blog and if learning was occurring the artefacts were the tools for that learning. The artefacts on the blog were text, videos, images and links to other websites, which may also include text, images and videos. However, the artefacts were skewed to some extent as the subjects were only permitted to upload text and broken links.

However, the artefacts were ostensibly linked to the other parts of the AT triad in this community. For example, the rules were such that only the news staff only could post images, videos and links to other websites. Therefore, the bloggers had only two options for uploading information: to use text and to post a broken link to another website. The link was broken possibly, but not definitely, to circumvent the censor so rules affected the types of artefacts that individuals provided.

The reasons for blogging influenced the extent to which someone provided artefacts and also the types of artefacts that they used. For example, bloggers who searched the web for information posted texts from other sites or links to other sites. However, participants who mostly wanted to read the information (albeit I did not interview anyone like this so it cannot be confirmed that they even existed) did not post any artefacts.

\section{Conclusion}

I was able to establish that the community encompassed all of the characteristics of an environment conducive to learning. When revisiting Colley, Hodkinson and Malcom (2002), a teacher was not involved; an assessment was not included; learning was possibly due to resistance or empowerment; learning is possibly implicit; the cite was no a formal educational site; it was learner-centred and the content was negotiated; learning is context specific; outcomes were not measurable; learning was communal; and engagement was open-ended. I would argue that learning could have taken place through seeking out information to repost on the blog and finding updates to post as well. The idea of learning by doing as described by Marsick (2009) applies to this scenario. The extent of learning, therefore, is fairly personal which substantiates the research conducted by McLoughlin and Lee (2010) and Schugurensky (2006). Some had a more passive function on the blog and therefore their purpose for joining was to seek information and therefore, learning was a central goal. The idea of the passive learner also substantiates the findings of Schugurensky (2006). 
Learning on the blog took place using cognitive and physical artefacts. Cognitive artefacts included reflection, activity, discourse and checking for accuracy. Physical were more evident and took the form of images, videos, links and text. These were limited to some extent depending on the rules of the community and the types of artefacts allowed and who was allowed to post certain artefacts. The types of artefacts used are depicted in Figure 3.

Figure 3 Learning artefacts used on this site (see online version for colours)

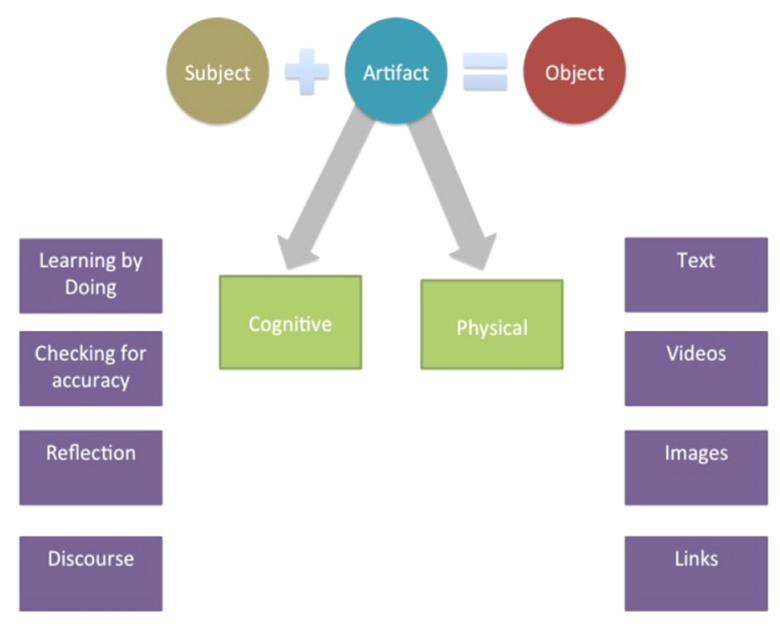

\section{Limitations}

The major limitation of this study was the lack of input from different types of stakeholders. While we interviewed and followed participants who varied in the quantity of their activity on the blogs, we were unable to interact with staff at the umbrella news organisation or the lurkers on the blogs. Therefore, we have no way of ascertaining informal learning on blogs from their perspective and therefore could not include this information in our findings. In addition, we were not able to interview bloggers who did align their beliefs with the majority, even though we were able to interact with them on the website at least initially. However, in order to have a complete understanding of the impact of the informal learning on the site, it would have been beneficial to collect data from their vantage point as well during interviews.

\section{Future research}

For future research, research should focus on the retention levels of informal or skills by subjects. Studies could also include in-depth research into the types of learning that occurs in social media would be useful as well. From this study, the most apparent types of learning were constructivist, situated and reflective. Each of these areas could be given a more focused analysis in future research. Along these same lines, the relationship 
between episodic memory (Koole, 2009) informal learning online could be given some attention. Koole (2009) believes that mobile learning supports episodic memory which is:

grounded in actual, authentic experiences such as traveling to foreign countries, visiting museums, visiting historic sites, and case studies in professional settings. Using concepts makes them active, and the ability of a learner to remember a concept is largely dependent upon the learner remembering its use (Koole, 2009, p.31).

This may help explain informal learning in online communities. Nevertheless, more research needs to be conducted through a variety of means - qualitative, mixed methods and quantitative research.

\section{References}

Attwell, G. (2007) 'Personal learning environments for creating, consuming, remixing and sharing. In Griffiths, D., Koper, R. and Liber, O. (Éds): Service Oriented Approaches and Lifelong Competence Development Infrastructures', Proceedings of the 2nd TENCompetence Open Workshop, pp.36-41.

Attwell, G. (2007b) 'Personal learning environments-the future of eLearning?', eLearning Papers, Vol. 2, No. 1, pp.1-7.

Bedny, G., Seglin, M. and Meister, D. (2000) 'Activity theory: history, research and application', Theoretical Issues in Ergonomics Science, Vol. 1, No. 2, pp.168-206.

Blanchard, A. (2008) Definition, Antecedents, and Outcomes of Successful Virtual Communities. Retrieved September 10, 2010 from http://www.psych.uncc.edu/alblanch/Blanchard_VC_ ENC.pdf.

Colley, H., Hodkinson, P. and Malcolm, J. (2002) Non-formal learning: mapping the conceptual terrain, a consultation report, University of Leeds, Leeds.

Crang, M. and Cook, I. (2007) Doing Ethnographies, Sage Publications, London.

Daniels, H. (2001) Vygotsky and Pedagogy, Routledge, London.

Driscoll, M. (2000) Psychology of Learning for Instruction, Allyn \& Bacon, Needham Heights, MA.

Emerson, R., Fretz, R., and Shaw, L. (1995). Writing Ethnographic Fieldnotes. Chicago: The University of Chicago Press.

Engestrom, Y. (2001). Activity Theory as a framework for the study of organizational transformations. Knowing in Practice Conference, Trenot, Italy.

Hung, D. (2002) 'Situated cognition and problem-based learning: implications for learning and instruction with technology', Journal of Interactive Learning Research, Vol. 13, No. 4, pp.393-414.

Jokisalo, E. and Riu, A. (2009) 'Informal learning in the era of Web 2.0', eLearning Papers, Vol. 14, p.5.

Jonassen, D. and Rohrer-Murphy, L. (1999) 'Activity theory as a framework for designing constructivist learning environments', Educational Technology, Research and Development, Vol. 47, No. 1, pp.61-79.

Koole, M.L. (2009) 'A model for framing mobile learning', Mobile Learning: Transforming the Delivery of Education and Training, Vol. 1, No. 2, pp.25-47.

Kuutti, K. (1996) 'Activity theory as a potential framework for human-computer interaction research', in Nardi, B. (Ed.): Context and Consciousness: Activity Theory and Human Computer Interaction, MIT Press, Cambridge, MA, pp.17-44. 
Laurillard, D. (2007) 'Pedagogical forms of mobile learning: framing research questions', in Mobile learning: Towards a research agenda. ed N. Pachler, WLE Centre, Institute of Education, London, pp.153-176.

Lave, J. and Wenger, E. (1991) Situated learning-legitimate peripheral participation: Legitimate peripheral participation, Cambridge University Press, New York.

Lecusay, R., Rossen, L. and Cole, M. (2008) 'Cultural-historical activity theory and the zone of proximal development in the study of idioculture design and implementation', Cognitive Systems Research, Vol. 9, nos. 1-2, pp.92-103.

Livingstone, D.W. (2001) Adults' Informal Learning: Definitions, Findings, Gaps, and Future Research, NALL Working Paper \#21.

Marsick, V. (2009) 'Toward a unifying framework to support informal learning theory, research and practice', Journal of Workplace Learning, Vol. 21, No. 4, pp.265-275.

McLoughlin, C. and Lee, M.J. (2010) 'Personalised and self regulated learning in the Web 2.0 era: international exemplars of innovative pedagogy using social software', Australasian Journal of Educational Technology, Vol. 26, No. 1, pp.28-43.

Mezirow, J. (1991) Transformative Dimensions of Adult Learning, Jossey-Bass, San Francisco, CA.

Nardi, B. (Ed.) (1996) Context and Consciousness: Activity Theory and Human-Computer Interaction, MIT Press, Cambridge.

Preece, J. (2001) 'Sociability and usability in online communities: determining and measuring success', Behavior and Information Technology, Vol. 20, No. 5, pp.347-356.

Rheingold, H. (1994) 'A slice of life in my virtual community', in Harasim, L.M. (Ed.): Global Networks: Computers and International Communication, MIT Press, Cambridge, MA, pp.57-80.

Rheingold, H. (1993) The Virtual Community. Retrieved April 8, 2012 from http://www.rheingold. $\mathrm{com} / \mathrm{vc} /$ book/.

Ritchie, J. and Lewis, J. (Eds.) (2003) Qualitative Research Practice: A Guide for Social Science Students and Researchers, Sage Publications, Thousand Oaks, CA.

Rubin, J. and Rubin, I. (2005) Qualitative Interviewing: The Art of Hearing Data, Sage Publications, Thousand Oaks, CA.

Schugurensky, D. (2006) 'Informal learning in local democracy', Learning in Places: The Informal Education Reader, Vol. 249, p.163.

Sicilia, M. and Palazón, M. (2008) 'Brand communities on the internet: a case study of CocaCola's Spanish virtual community', Corporate Communications: An International Journal, Vol. 13, No. 3, pp.255-270.

Selwyn, N. (2008) 'Web 2.0 applications as alternative environments for informal learning - a critical review', CD-KERIS Expert Meeting. Alternative Learning Environments in Practice: Using ICT to Change Impact and Outcomes, Cheju Island, South Korea.

Siemens, G. (2005a) 'A learning theory for the digital age', Instructional Technology and Distance Education, Vol. 2, No. 1, pp.3-10.

Spradley, J.R. (1980) Participant Observation, Wadsworth/Thomson Learning, Belmont, CA.

Spradley, J.P. (1979) The ethnographic review, Holt, Rinehart and Winston, New York.

Stone, A.R. (1991) 'Will the real body please stand up?', in Benedikt, M. (Ed.): Cyberspace First Steps, MIT Press, Cambridge, pp.81-118.

Tsekeris, C. and Koskinas, K. (2011) 'General reflections on virtual communities research', China Media Research, Vol. 7, No. 1, pp.39-47.

Vygotsky, L.S. (1978) 'Mind in society: the development of higher psychological processes Cambridge, Mass.: Harvard University Press.

Wilson, B.G. (1995) Metaphors for Instruction: Why We Talk About Learning Environments, Vol. 35, Educational Technology, Saddle Brook, NJ, pp.25-25. 
World Wide Web Foundation (n.d.). Internet Live Stats, Retrieved December 16, 2014, from http://www.internetlivestats.com/total-number-of-websites/.

Ziegler, M.F., Paulus, T. and Woodside, M. (2014) 'Understanding informal group learning in online communities through discourse analysis', Adult Education Quarterly, Vol. 64, No. 1, pp.60-78. 